\title{
QUARTER CAR SUSPENSION SYSTEM WITH ONE DEGREE OF FREEDOM SIMULATED USING SIMULINK
}

\author{
L. Bereteu, A. Perescu \\ Mechanical and Vibration Department, University "Politehnica”, M. Viteazu 1, RO-300222, Timișoara, \\ Romania
}

Article Info

Received: 28 December 2011 Accepted: 19 January 2012

Keywords: automotive suspension, stiffness, damping, simulate.

\begin{abstract}
Simulate the behavior of a quarter car suspension system with Simulink ${ }^{\circledR}$. Consider only vertical movement of the car, neglecting roll and pitch. All movements of the car axes are modeled as having equal amplitude. The characteristic equations that describe the behavior of dynamical systems based on FBD (Free Body Diagram) of automotive suspension. We make the simulation model in six steps. In simulation we consider the damping coefficient, $c$, variable. The rest of parameters are constant (mass, speed and stiffness). The simulation parametrs are defined in Mathlab ${ }^{\circledR}$. We follow the final signal created on the oscilloscope. At the end of the study, we concluded the effect of damping coefficient changes over the comfort.
\end{abstract}

\section{Introduction}

The quarter car has been for a long time the par excellence model used in suspension design. It is a very simple model as it can only represent the bounce motion without taking into account pitch or roll vibration modes. However it is very useful for a preliminary design.[1]

The response time of a suspension system for a vehicle can be analyzed by a simplified model like a system consisting of mass, spring and damper as shown in Figure 1. Assumptions: It considers only vertical movement of the car (without roll or pitch); It is assumed that the spring mass and the dumper mass are negligible; It ignors the tire mass and its damping properties; The input to the car wheel can be modeled as a sum of functions in two stages, the first function is the enter into the pit, and a second function is the exit from the pit.[2] 


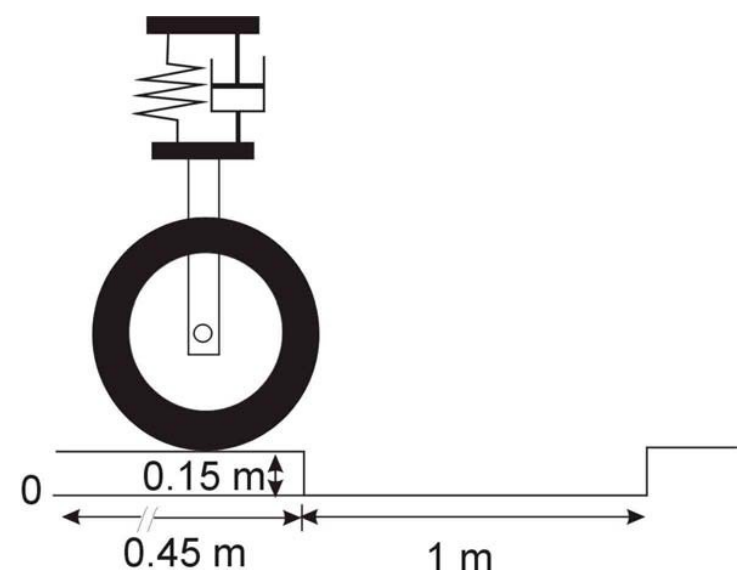

Fig. 1. Simplified model of suspension

Consider the parameters: Vertical movement of the car (the pit depth) is $0.15 \mathrm{~m}$; The input function is the initial step function starts after a horizontal desplacement of $450 \mathrm{~m}$ from vertical movement of $0 \mathrm{~m}$, decreased to the level of $-0,15 \mathrm{~m}$, and then returns to $0 \mathrm{~m}$ after a horizontal movement of $1 \mathrm{~m}$; The car tire has a diameter of $0.305 \mathrm{~m}$; The speed of the car is $20 \mathrm{~m} / \mathrm{s}(72 \mathrm{~km} / \mathrm{h})$.

\section{Method and Samples}

This model takes into account only vertical movement and all movements of the car axes are modeled as having equal amplitude and occur at the same time to eliminate the need to calculate the pitch and roll of the vehicle. First are identified the state variables. The following are established the characteristic equations that describe the behavior of dynamical systems based on FBD (Free Body Diagram) of automotive suspension system as in Figure 2. $[5,7]$

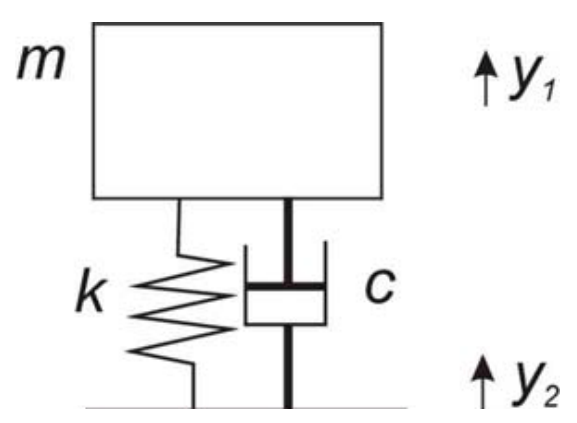

Fig. 2. FBD of suspension system

Where: $m_{m}$ is the weight of the car (unsprung mass), $k$ is the spring constant, $c$ is the damping constant, $y_{2}$ is the perturbation of the road and $y_{1}$ is the body movement.

The characteristic equation:

$$
m_{m} \ddot{y_{1}}+c \dot{y}_{1}+k\left(y_{1}-y_{2}\right)=0
$$

Note: gravity is canceled by the initial displacement of springs. 
State variables:

$$
\ddot{y}_{1}=\frac{c \dot{y}_{1}-k\left(y_{1}-y_{2}\right)}{m_{m}}
$$

Input:

$$
y_{2}=\left\{\begin{array}{c}
0 m \quad t<h_{-} \text {start } \\
-0.15 m \quad h_{-} \text {start } \leq t<h_{-} \text {end } \\
0 m \quad t \geq h_{-} \text {end }
\end{array}\right.
$$

$h \_s t a r t$ and $h \_$end correspond to moment of time at witch the tire starts the entry in the pit and exit from it.

To achieve the model of suspension in Simulink, I follow the diagram from Figure 3.[6]

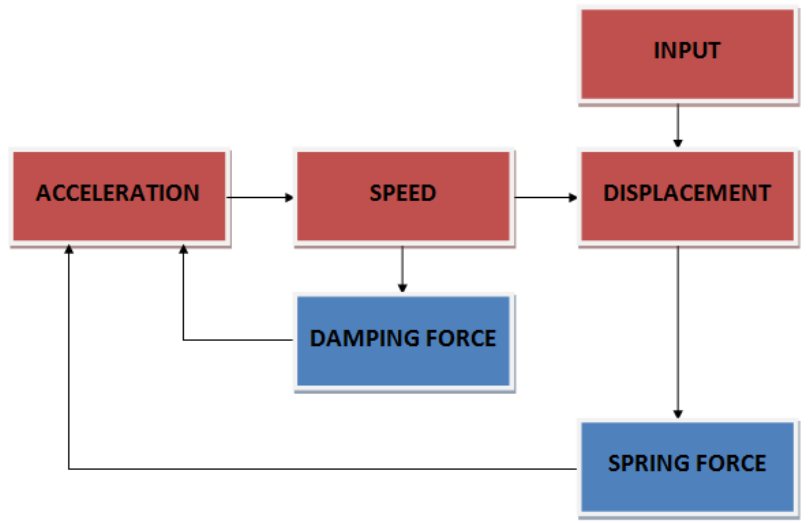

Fig. 3. Diagram of suspension system for Simulink

Model suspension system includes six steps. Step 1: The effect of the wheel on the entrance into the pit is simulated by adding two step functions, Step 1 and Step 2 together with the summation block. Step 2: Insert an integration block for converting acceleration in speed and speed in displacement. Step 3, 4 and 5: Enter three gain blocks, one for spring force, other for damping force and last for the body weghit. In addition introduces three summing blocks. Step 6: Insert one scope block and one "To file" block. The complet system is shown in Figure 4.[3]

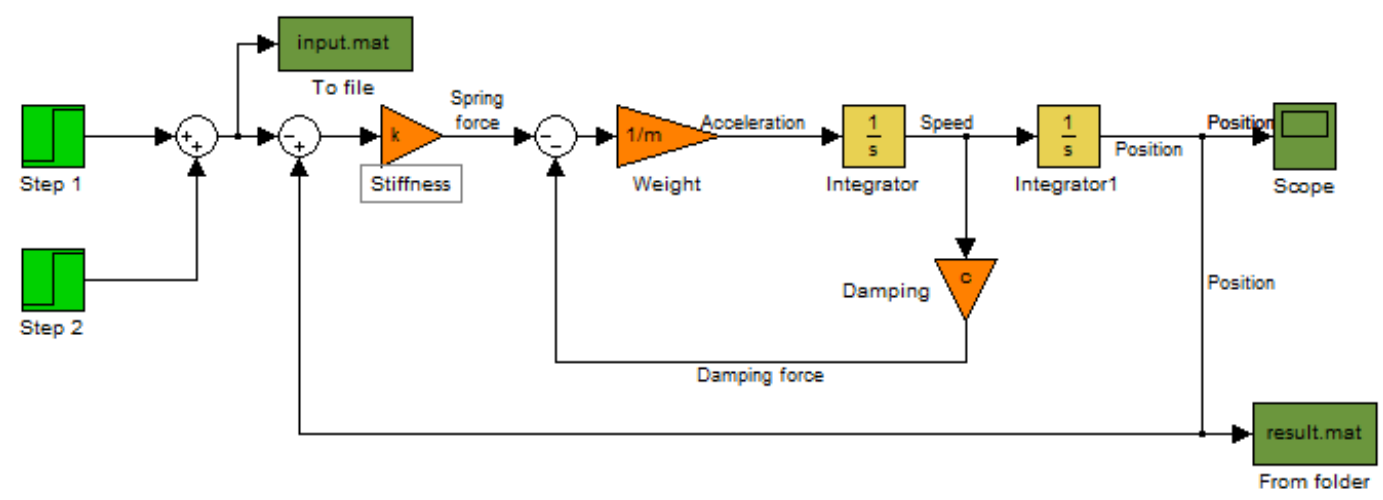

Fig. 4. Diagram of suspension system in Simulink 
The simulation parameters are defined in Matlab:

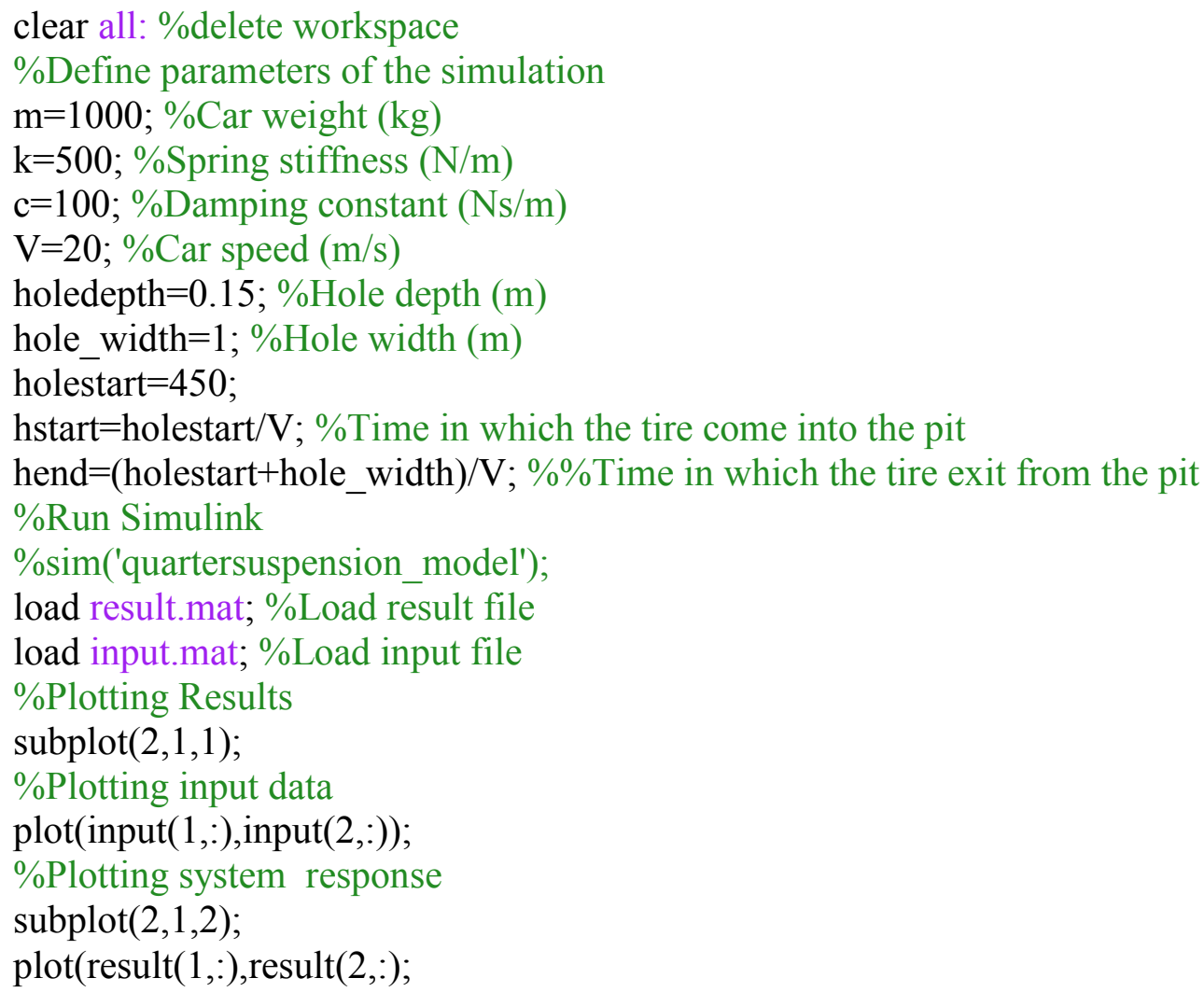

\section{Results and Discussions}

Follow the finaly signal created in Simulink restored on the oscilloscope. For each case we consider the diagram from Figure 5.

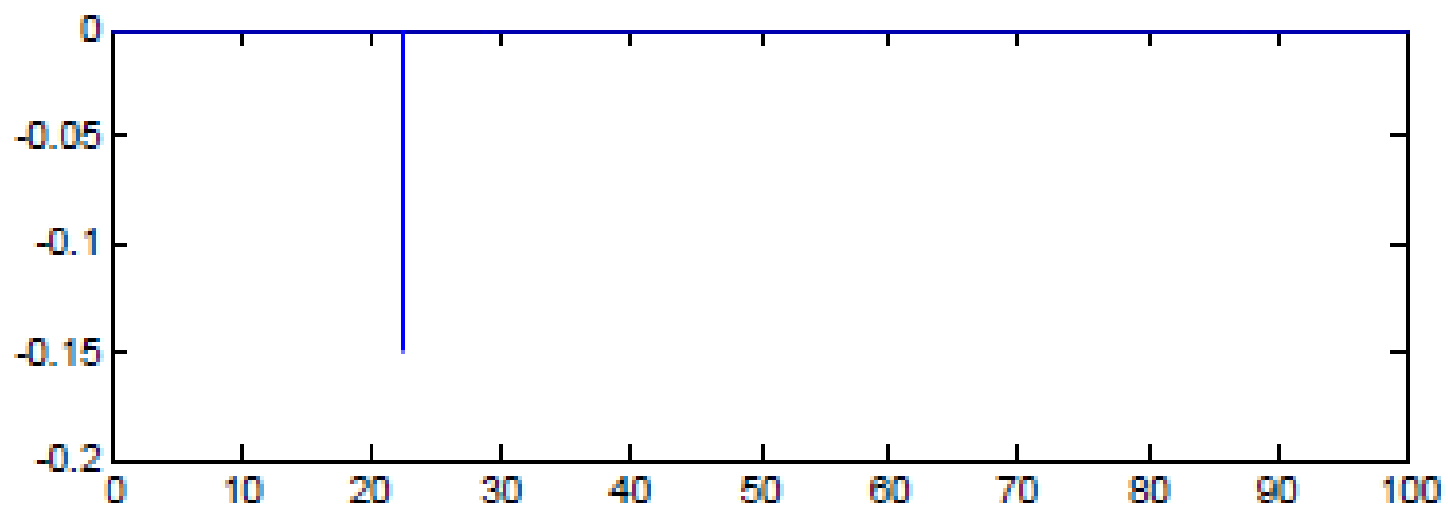

Fig. 5. The input of the wheel in the pit

Consider the damping coefficient, $c$, variable. The rest of parameters are considered constant: $m=1000 \mathrm{~kg}, V=20 \mathrm{~m} / \mathrm{s}$ and $k=500 \mathrm{~N} / \mathrm{m}$. In the simulation we consider six different cases for damping coefficient: without damping $c=0 \mathrm{Ns} / \mathrm{m}$ shown in Figure 6 , with lower damping $c=10 \mathrm{Ns} / \mathrm{m}$ shown in Figure 7 , with optimal damping $c=100 \mathrm{Ns} / \mathrm{m}$ shown in Figure 8, with increased damping $c=500 \mathrm{Ns} / \mathrm{m}$ shown in Figure 9, with higher damping shown in Figure 
10 and in the last case we consider overcritical damping $c=1500 \mathrm{Ns} / \mathrm{m}$, shown in Figure 11 . We consider this damping coefficient overcritical for stiffness $k=500 \mathrm{~N} / \mathrm{m}$ and weight $m=1000 \mathrm{~kg}$. Critical damping coefficient is determined by the formula: $c_{c r}=2 \sqrt{\mathrm{km}}$ and result $c_{c r}=1414.213 \mathrm{Ns} / \mathrm{m}$. In this simulation we consider $c>c_{c r}$.

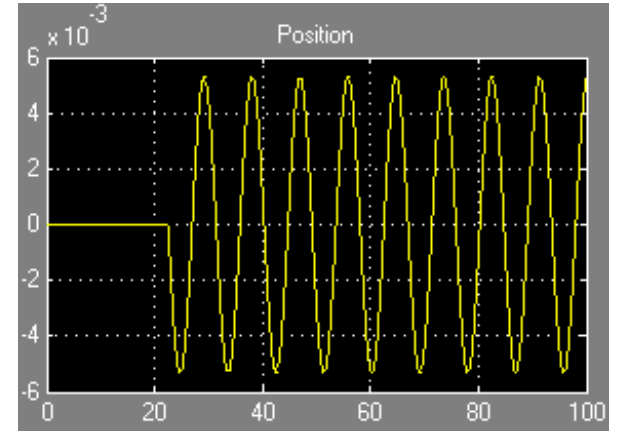

Fig. 6. Response without damping

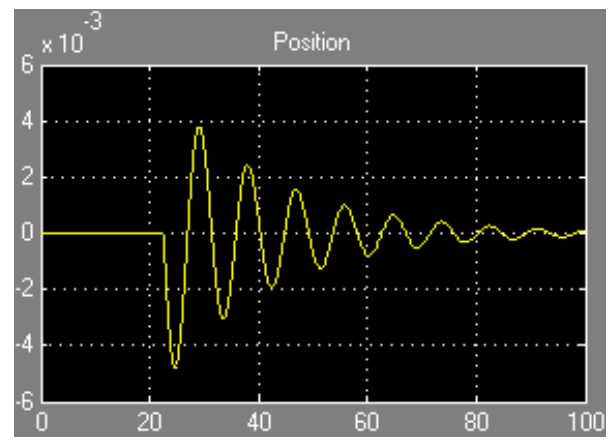

Fig. 8. Response with optimal damping

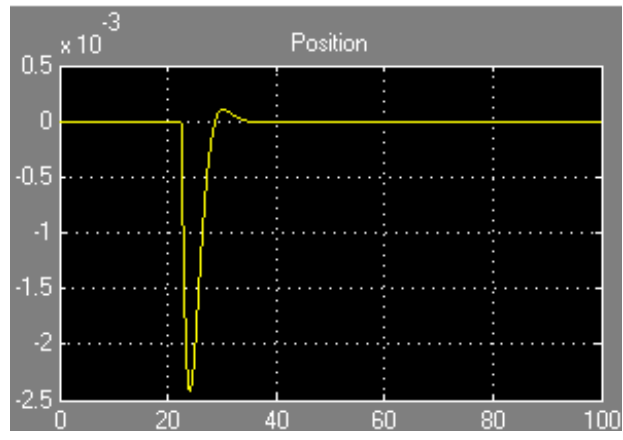

Fig. 10. Response with higher damping

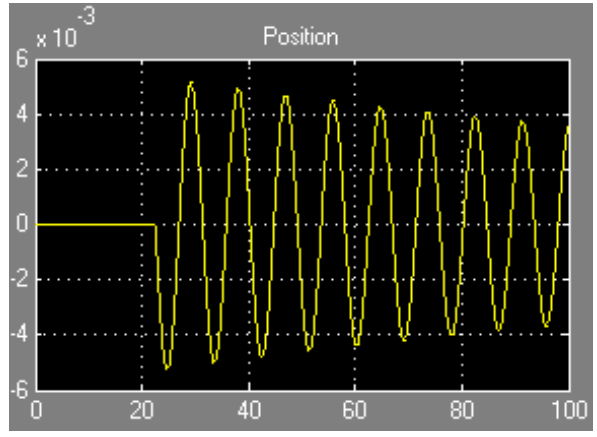

Fig. 7. Response with lower damping

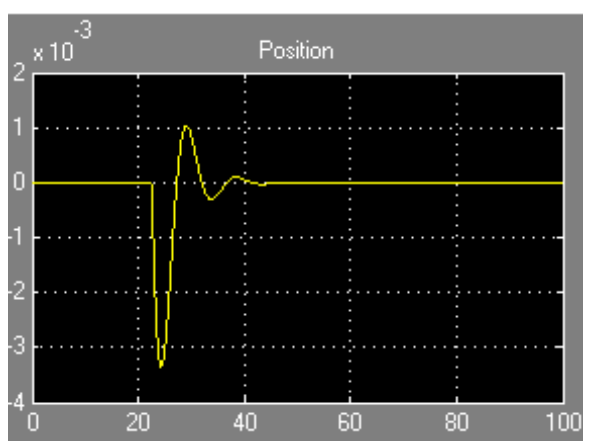

Fig. 9. Response with increased damping

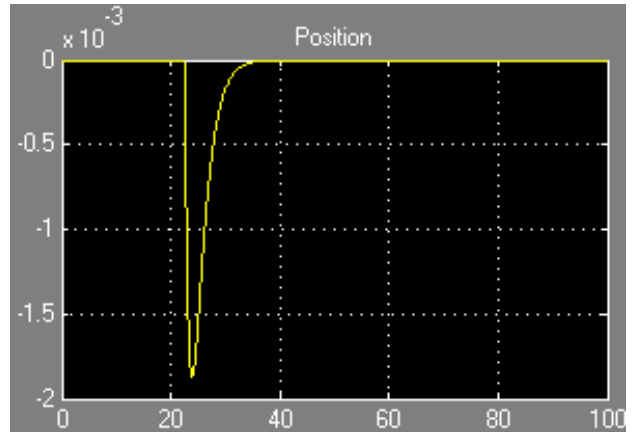

Fig. 11. Response with overcritical damping

\section{Conclusions}

When $c=10 \mathrm{Ns} / \mathrm{m}$, the lack of damping leads to an uncomfortable ride, when $c=100 \mathrm{Ns} / \mathrm{m}$, the system has improved damping characteristics and when $c=500 \mathrm{Ns} / \mathrm{m}$ the damping difficult produces reverberations and displacements. If the damping coefficient increases, the amount of reverberations in the system is reduced. With this simulation software may be imagine various situations similar to the real environment, thus saving money and time. 


\section{References}

[1] E. Guglielmino, C. W. Stammers, T. Sireteanu, G. Ghita, M. Giuclea, Semi-active Suspension Control, Springer, London (2008);

[2] E. M. Lowndes, Development of an Intermediate DOF Vehicle Dynamics Model for Optimal Design Studies, Thesis for the Degree of Doctor of Philosophy, North Carolina (1998);

[3] G. Rill, Vehicle Dynamics, Lecture Notes, Regensburg (2003);

[4] H. Heisler, Advanced Vehicle Tehnology, Butterworth Heinemann, Oxford (2002);

[5] R. Gao, Dynamic System Modeling Using Matlab and Simulink, MIE397B: Dynamic System Modeling, Analysis, and Simulation (2007);

[6] R. N. Jazar, Vehicle Dynamics: Theory and Applications, Springer, London (2008);

[7] T. D. Gillespie, Fundamentals of Vehicle Dynamics, Society of Automotive Engineers, Warrendale. 